\title{
La Roseta Hexapétala y la Cruz Solar en Ilobasco
}

\author{
Ernesto Rivas Arévalo \\ Centro de documentación, Universidad Radboud \\ rivsernesto@gmail.com
}

URI: http://hdl.handle.net/11298/381

DOI: http://dx.doi.org/10.5377/koot.v0i8.5849

\section{Resumen}

La Roseta Hexapétala es una figura geométrica ligada a la ciudad de Ilobasco, el autor valiéndose de ejemplos, nos da una explicación resumida del valor místico de este símbolo, de su incorporación al cristianismo, de su influencia en la cultura popular como elemento decorativo, de sus múltiples significados; así de sus orígenes.

Palabras clave: Historia, símbolo, cultura, identidad, localidad.

\begin{abstract}
The Six-petal rosette is a geometric shape associated to the city of Ilobasco. Moreover, the author provides a brief explanation of the mystical value of this symbol by using examples; he talks about its incorporation into Christianity, its influence on popular culture as a decorative element, its multiple meanings as well as its origins.
\end{abstract}

Keywords: History, symbol, culture, identity, town

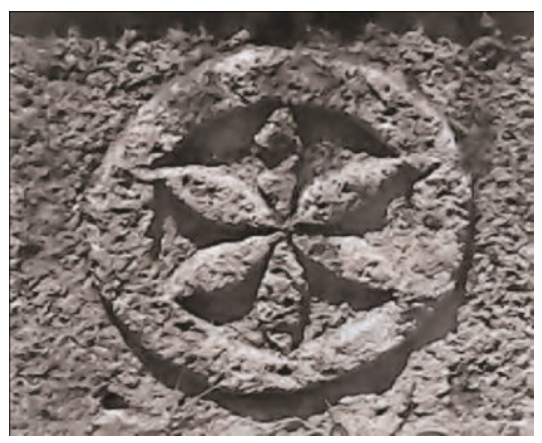

La Roseta Hexapétala

The Six-petal rosette 
En los años 70 en Ilobasco, mientras los trabajadores realizaban trabajos excavación para la remodelación de aguas negras y la adoquinación de las calles alrededor del parque, hicieron un hallazgo inesperado. Frente a la iglesia de San Miguel Arcángel encontraron algunas piedras con la Roseta Hexapétala enmarcada en un círculo y esculpida en los cuatro lados de cada piedra. Las piedras, en la parte superior, también tenían esculpidas la Cruz Solar. Con gran probabilidad, las piedras pertenecen al mismo periodo y son del mismo tamaño. Algunas de ellas están deterioradas, pero todas tienen la misma ornamentación. Las basas, lógicamente, formaban parte de las columnas de la iglesia anterior a la que actualmente conocemos.

Durante años, las piedras anduvieron deambulando de un lado a otro por toda la ciudad hasta el grado de llegarse a pensar que no se sabía qué hacer con ellas. Afortunadamente, finalmente, a las piedras se le dio un puesto fijo, un lugar bastante aceptable. Actualmente se encuentran en el atrio de la iglesia del centro de Ilobasco, pero sin ninguna placa explicativa que oriente al turista curioso, cosa que por allí se debería comenzar.

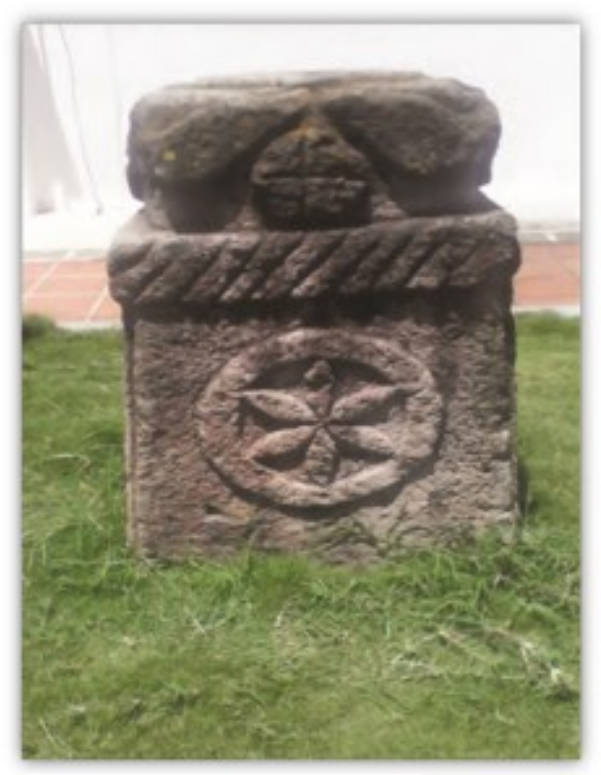

Fotografía Eduardo Rivas 


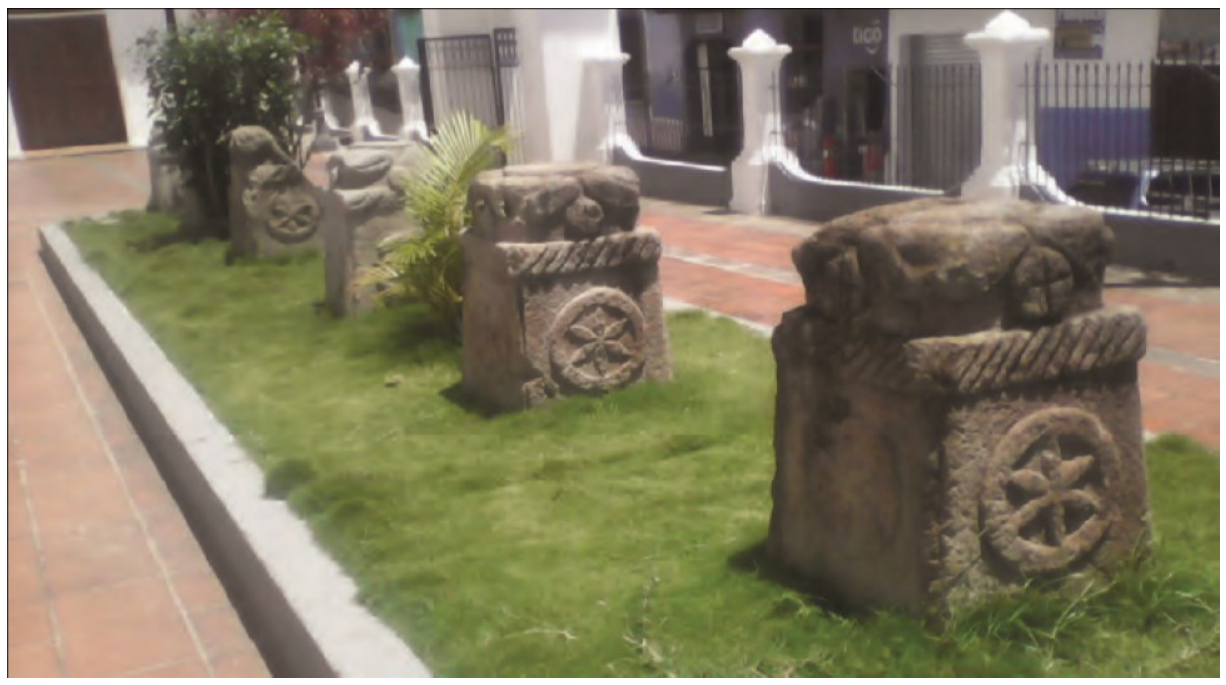

Fotografía Eduardo Rivas

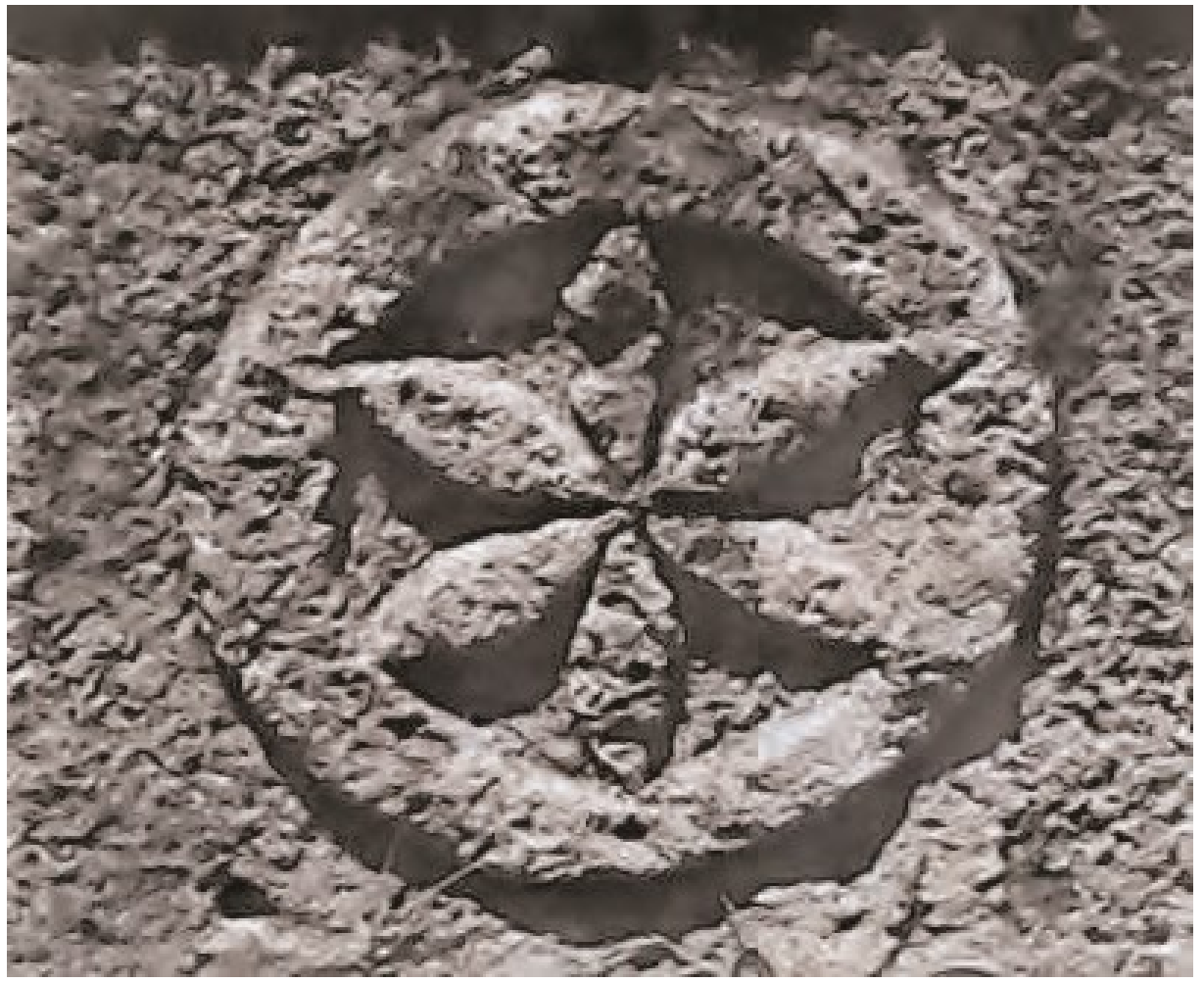

\section{Fotografía Eduardo Rivas}

CUniversidad Tecnológica de El Salvador 


\section{La Roseta Hexapétala}

La Roseta Hexapétala1(o flor de seis pétalos), esculpida en las basas, es una figura concéntrica, geométrica, de seis partes iguales que fácilmente se puede trazar con un compás. La figura es muy conocida como parte de la arquitectura popular, ligada a la superstición popular y lo mismo puede representar una flor que una estrella. Sus antecedentes se remontan a tiempos inmemoriales y es una herencia de los pueblos antiguos indoeuropeos. Algunas de ellas datan de los siglos IV o V a. C2.

Aunque puede ser visto como aporte cultural español, en esencia, el origen la Roseta Hexapétala no tiene nada que ver con la península ibérica, aunque esté muy presente en esa región europea. Su origen pagano está ligado a la Edad de Bronce, a la protohistoria, a culturas prerrománicas como los celtas y godos. Por tal razón, no es raro encontrar en diversidad de lugares de Europa vestigios arquitectónicos incorporando la Roseta Hexapétala, ya sea en iglesias, como parte de estelas funerarias, o simplemente como elementos decorativos de muebles, en la parte central del dintel de las puertas en casas de labranza en España,3 en capiteles; así como en numerosas estelas discoidales, etc.. Algunas de ellas con variantes, con adornos como la estela de Agüero en Huesca4, en la parte norte de España, en Los Pirineos. Así como también las innumerables estelas encontradas en el País Vasco.

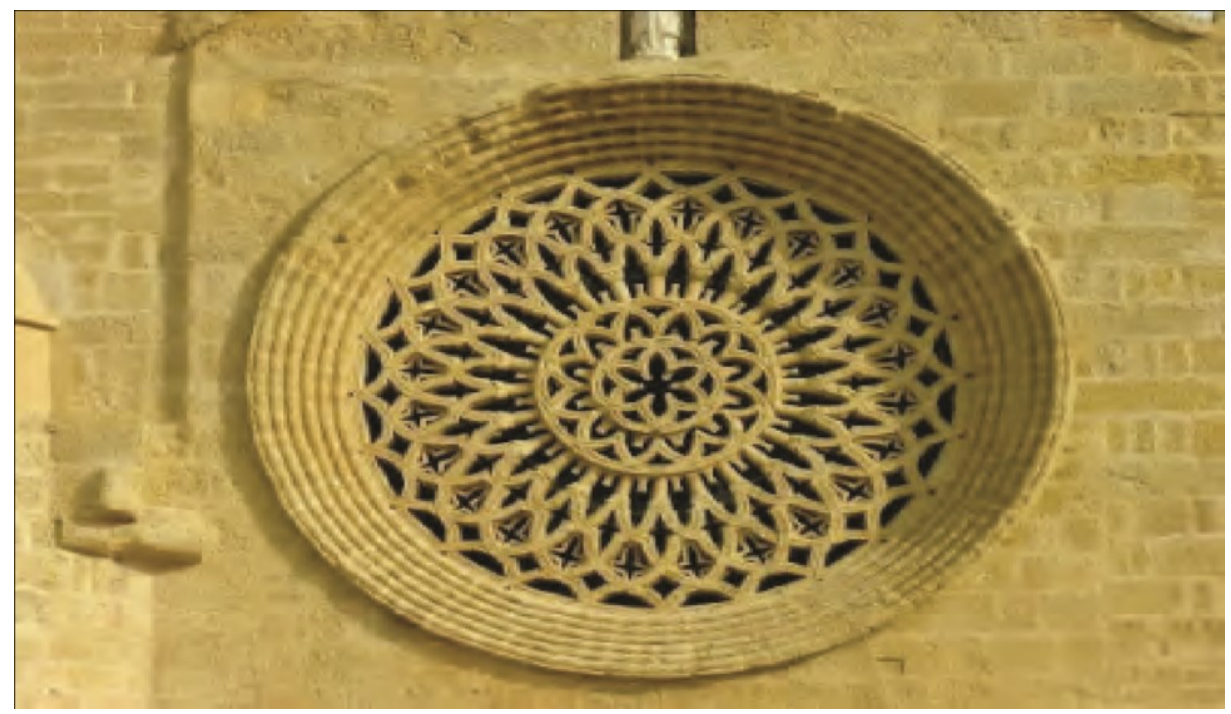

Fotografía Rafael Alarcón Herrera. Esta foto de la fachada principal del templo de San Lorenzo en Córdoba muestra un imponente rosetón, quizás uno de los más bellos y mejores ejemplos de la valorización de este símbolo. 
No se sabe a ciencia cierta su integración al cristianismo, pero es lógico pensar que probablemente esta clase de símbolos fueron heredados por la cultura romana de pueblos prerromanos y más tarde integrados por la religión cristiana. El uso de estos símbolos se expandió más en la Edad Media en regiones como Francia, España y Portugal donde ya existía desde tiempos remotos. Como ornamento se ha popularizado tanto, que en el trayecto de la historia, un gran número de artesanos ha trabajado el símbolo en materiales como piedra, cuero, madera, etc.

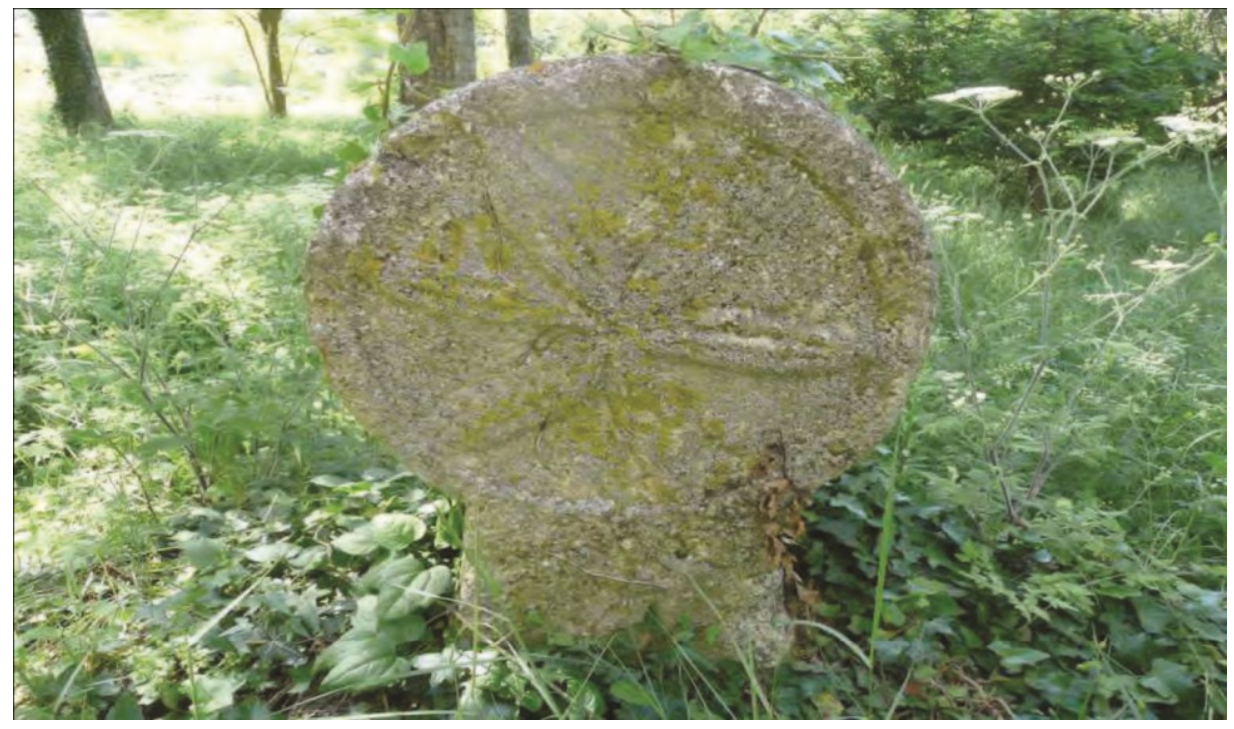

Fotografía de Jesús M ${ }^{a}$ Díaz Gómez... La estela pétrea es usada en este contexto como parte del simbolismo funerario. Esta estela está situada junto a la portada de entrada a la iglesia de San Bartolomé de Gollano, pueblecito del Valle de Améscoa (Navarra). España.

\section{Significado cósmico y religioso}

La Roseta Hexapétala está históricamente muy presente en la cultura popular europea. El símbolo se ha usado en diferentes culturas con múltiples significados, ya sea en sentido mágico o religioso. Por esta diversidad y riqueza de interpretaciones, no se considera un simple motivo ornamental sino un elemento de espiritualidad, parte de la iconografía solar6; un ideograma astral, de naturaleza religiosa que hace referencia a la luz eterna de Dios, al acompañamiento funerario como símbolo de reencarnación, símbolo de fe o de protección contra fuerzas malignas. 
José Manuel Gómez-Tabanera la interpreta como un símbolo de inmortalidad 7. El centro de la flor representa el origen, el principio, 8 el punto de partida y el punto de llegada, el centro cósmico. El disco, la rueda entorno, implica movimiento, rotación, cambio constante, cíclico.

Debemos admitir que algunas de estas interpretaciones tienen un carácter hipotético, pero eso no le quita la esencia de su valor espiritual y su importancia histórica. La Hexapétala va más allá de ser un motivo ornamental. La variedad de significados que reúne este símbolo, engloba también otros símbolos de origen celta, como son el Trisquel y el Tetrasquel, símbolos también ampliamente estudiados dentro de la cultura popular.

\section{La Cruz Solar}

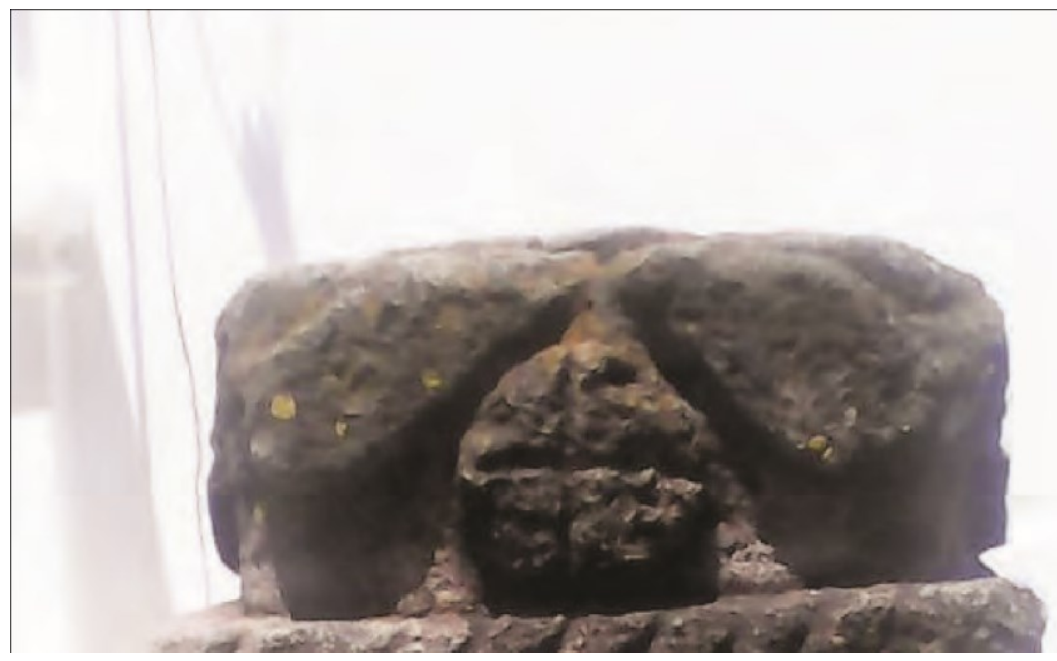

Otro de los símbolos esculpidos en la parte superior de las piedras de Ilobasco, es la Cruz Solar. La Cruz Solar es uno de los símbolos más arcaicos que se conocen en la historia de la humanidad. Por su simplicidad, la cruz, desde la antigüedad ha estado presente en muchas partes del mundo y en diferentes culturas, aún mucho antes de la cristiandad. En otras palabras, es un símbolo universal ligado a leyendas, a la religiosidad del ser humano y a la naturaleza misma.

Como hemos dicho anteriormente, cuando hablábamos de la Roseta Hexapétala, el círculo representa el movimiento, el dinamismo cambiante de la vida. Existe una diversidad de interpretaciones asociadas con la Cruz Solar: con el árbol de la vida, con las estaciones del año, etc... Dejando de lado cualquier otra interpretación, ésta me parece la más sencilla de todas: 


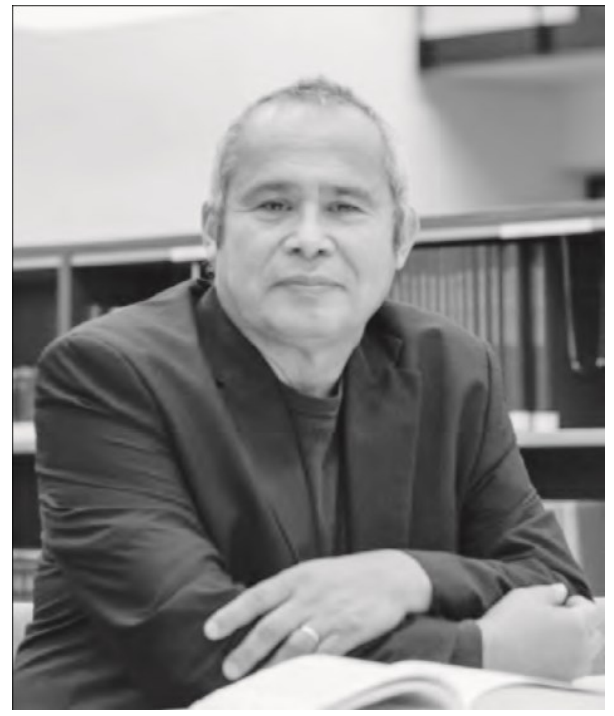

Ernesto Rivas Arévalo

"El punto en el centro de la cruz nos indica al Ser, alrededor del cual gira la cruz. Los elementos son: tierra, agua, aire, fuego. [.....]. Se ha usado para representar las cuatro direcciones, los cuatro elementos, la tierra, los cuatro vientos, etcétera. ${ }^{9}$ "

El antropólogo Ramón D. Rivas, ${ }^{10}$ haciendo mención de la pila bautismal de la iglesia de San Miguel Arcángel de Ilobasco, nos dice que la pila bautismal data de la misma época en que se construyó la iglesia. Tal aseveración nos evidencia que las basas encontradas frente a la iglesia, bien podrían pertenecer al mismo periodo (1640-1660). Es evidente que tal argumento nos da el camino para establecer una relación entre la pila bautismal y las piedras. A mi juicio, requiere mayor estudio. Ideal sería hacer un estudio en base a carbono 14 que nos dé informaciones más exactas.

Las piedras forman parte de patrimonio cultural ilobasquense y conjuntamente con la pila bautismal, pueden ser el primer paso para el inicio de un museo. Afortunadamente ya se empieza a tener más conciencia de su importancia y del valor histórico de esas piezas arqueológicas. 


\section{Referentes bibliográficos}

La Hexapetala se conoce con diversidad de nombres: flor galana, exfolia, flor Hexapétala, ruedecilla céltica, flor del agua, flor rosácea, roseta de seis pétalos, roseta de seis puntas, rosa hexafolia, etc...

http://www.cromlechycaminodesantiago.com/p/retazo.html

Muchos ejemplos se pueden encontrar en la región de La Mancha, Castilla y León.

http://www.cromlechycaminodesantiago.com/p/retazo.html

El licenciado Jesús $\mathrm{M}^{\mathrm{a}}$ Díaz Gómez es un renombrado investigador del arte y mitología española.

María Paz García-Gelabert Pérez, Consideraciones acerca de la iconografía solar. Pervivencias, Hispania Antiqva XXXVI pp. 195-220. 2012.

GÓMEZ-TABANERA, J. M. "Mito y simbolismo en las Estelas funerarias discoideas de la Península Ibérica", en FRANKOWSKI, E. et alii. Estelas discoideas de la Península Ibérica, Madrid, Ediciones Istmo \& José M. Gómez-Tabanera, Págs. 249-292. 1989.

Manuel Valle, LA ROSETA HEXAPÉTALA, http://villadesosdelreycatolico. blogspot.nl/2016/04/la-roseta-hexapetala.html

https://santuariodelalba.wordpress.com/2016/10/28/la-cruz-solar-lacuadratura-del-circulo/

Ramón D. Rivas, Ilobasco de los recuerdos, Tecnoimpresos, S. A. de C.V., Universidad Tecnológica de El Salvador, segunda edición, Pág 20. diciembre, 2016. 


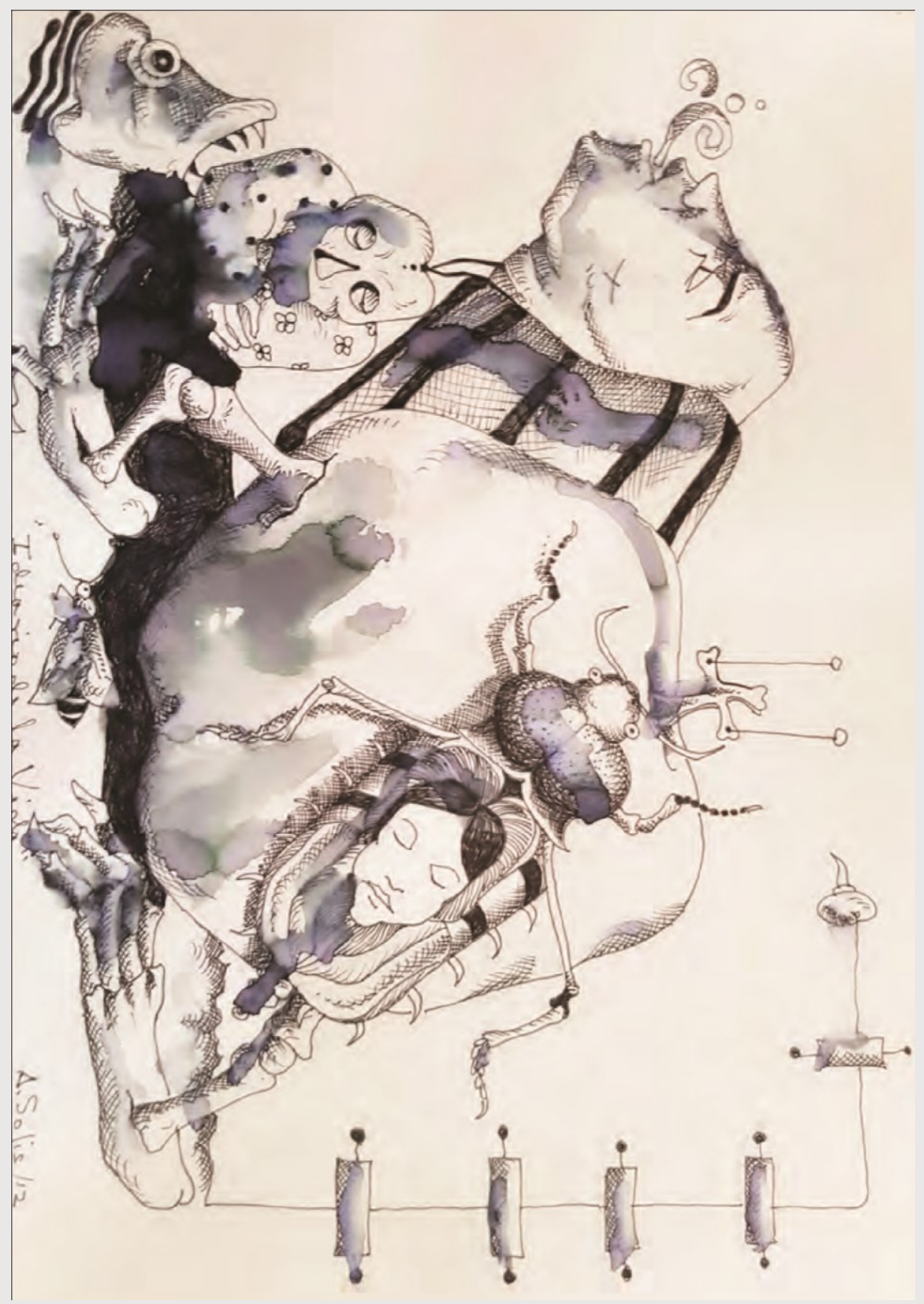

Armando Solis 